\title{
MULTICULTURALISMO E FORMAÇÃO DOCENTE EM ESPANHOL: 0 currículo como resistência
}

Mirian Ferreira Grees

(UFF)

https://orcid.org/0000-0003-3574-2621

\section{RESUMO}

A partir das grades curriculares e ementas do curso de licenciatura em Letras/Espanhol de quatro universidades públicas do Estado do Rio de Janeiro (Universidade Federal Rural do Rio de Janeiro, Universidade Federal do Rio de Janeiro, Universidade Federal Fluminense e Universidade do Estado do Rio de Janeiro), o presente trabalho busca contribuir para o currículo multicultural crítico na formação docente, observando os sentidos produzidos através do currículo e refletindo sobre as construções discursivas e a falta de representação cultural no currículo oficial. Após o recolhimento do corpus, comparamos e analisamos os diferentes tipos de multiculturalismo encontrados. Em nossa pesquisa documental, percebemos que mesmo o tema tendo crescido nos últimos anos, o currículo ainda privilegia o ensino de determinadas culturas e a diversidade cultural existente continua sendo apagada.

PALAVRAS-CHAVE: currículo; discurso; multiculturalismo; formação docente. 


\section{MULTICULTURALISM AND TEACHING TRAINING IN SPANISH: The curriculum as resistance}

\section{ABSTRACT}

From the curricular grades and menus of the licentiate course in Letters / Spanish from four public universities in the state of Rio de Janeiro (University Federal Rural of Rio de Janeiro, University Federal of Rio de Janeiro, University Federal Fluminense and University of Estado of Rio de Janeiro), the present work seeks to contribute to the critical multicultural curriculum in teacher education, observing the meanings produced through the curriculum and reflecting on the discursive constructions and lack of cultural representation in the official curriculum. After the recollection of the corpus, we compared and analysed the different types of multiculturalism found. In our documentary research, we realized that even the theme having grown in recent years, the curriculum still privileges the teaching of certain cultures and the existing cultural diversity continues to be erase.

KEYWORDS: curriculum; speech; multiculturalism; teacher training. 


\section{1 lntrodução}

O debate acerca do currículo tem sido frequente nos últimos anos. Diferentes perspectivas vêm demonstrando interesses na sua construção. No entanto, ainda é preciso discutir a importância do processo de representação na sociedade, trabalhando com os discursos nele produzidos, de forma que as identidades plurais e não fixas possam ser reconhecidas e não apenas valorizadas.

Neste trabalho, consideramos algumas perguntas centrais quanto à questão cultural: como se organiza a grade curricular na formação do curso de Letras/Espanhol das universidades investigadas? Que conteúdos são apresentados nas ementas das disciplinas de cultura nas diferentes faculdades? Qual tipo de abordagem multicultural está presente nas ementas dessas disciplinas?

Para responder a esses questionamentos, utilizamos os postulados teóricos de Tomaz Tadeu da Silva (2001), que trata da crise de representação e seu vínculo com as relações de poder, como também das teorias do currículo; dos conceitos de Fairclough (2001), que apresentou uma importante contribuição para os estudos de análise crítica do discurso; das teorias do sociólogo Stuart Hall (2006), uma vez que o autor nos trouxe reflexões acerca das identidades fragmentadas pós-modernas; além de McLaren (2000), que fomenta a reflexão sobre os tipos de multiculturalismo.

Esta pesquisa tem como objetivos verificar a perspectiva multicultural trabalhada na formação docente e contribuir para a construção de um currículo de resistência, pois acreditamos que refletir sobre um currículo multicultural crítico, que trate das diferentes vozes dentro do ensino de línguas, no âmbito da graduação, torna-se emergente à medida que ainda notamos a falta de representação dos sujeitos que estão à margem em nossa sociedade.

Em conformidade com os objetivos deste trabalho, utilizamos como metodologia a pesquisa documental, que segundo PÁDUA (1997, p. 62), "é aquela realizada a partir de documentos, contemporâneos ou retrospectivos, considerados cientificamente autênticos (não fraudados)", trata-se de uma pesquisa qualitativa e intencional, visando à comparação ou à descrição.

Quanto ao procedimento metodológico, nos valemos como corpus das grades curriculares e ementas das disciplinas relacionadas à cultura de quatro universidades públicas do Estado do Rio de Janeiro, do ano vigente. 
Fizemos, então, uma análise comparativa entre elas, além de buscar reconhecer os tipos de multiculturalismos presentes nesses documentos a partir da classificação proposta por McLaren (2000).

Consideramos que refletir sobre o ensino de língua espanhola e ampliar o tema multiculturalismo são ações importantes para a contribuição de uma formação docente mais política e preocupada com a diversidade cultural.

\section{2 língua e discurso: práticas sociais}

As noções de língua vêm sendo debatidas nas últimas décadas por diversos estudiosos da área da linguagem. Saussure, o precursor dos estudos linguísticos, se dedicou exclusivamente a langue ${ }^{1}$, pois acreditava em um sistema estruturalista em que não cabia a parole ${ }^{2}$, visto que essa era, em sua perspectiva, individual. (SILVA \& KOCHE, 1983).

Com o decorrer dos anos, surgem novas perspectivas à medida que deixamos de perceber a língua como somente um sistema estruturalista e passamos a entendê-la como prática social, assim como o discurso.

De acordo com os preceitos de BAKHTIN (1997, p. 289), “ $A$ língua se deduz da necessidade do homem de expressar-se, de exteriorizar-se. A essência da língua, de uma forma ou de outra, resume-se à criatividade espiritual do indivíduo." Ou seja, a língua é uma das formas que utilizamos para nos comunicarmos e não está baseada puramente em estruturas, mas, sim, em processos de criatividade e de construção social.

$\mathrm{Na}$ perspectiva bakhtiniana, a língua, portanto, depende de uma interação verbal entre os indivíduos, através de enunciados e, cria dialogismos, que, segundo o autor supracitado, é basicamente uma "conversa" entre textos lidos e vozes discursivas com as quais o sujeito interagiu na sua vida e reproduz em forma de outros textos.

Com relação ao discurso, o linguista FAIRCLOUGH (2001, p. 91), que apresentou uma importante contribuição para os estudos de análise crítica do discurso, relacionando-o com as esferas sociais, nos explica que:

\footnotetext{
${ }^{1}$ Saussure utilizava a palavra "langue" para fazer referência à língua em seu sistema estrutural.

2 "Parole" é a fala individual de cada indivíduo. "Langue" e "parole" é uma das dicotomias de Saussure.
} 
O discurso contribui para a constituição de todas as dimensões da estrutura social que, direta ou indiretamente, o moldam e o restringem: suas próprias normas e convenções, como também relações, identidades e instituições que lhe são subjacentes. O discurso é uma prática, não apenas de representação do mundo, mas de significação do mundo, constituindo e construindo o mundo em significado.

O autor ressalta que por ser prática social, o discurso não é individual e nem depende só do contexto de fala. Ele é moldado, político, ideológico, representativo e, portanto, constrói significações no imaginário do outro, que pode ou não reproduzi-lo.

É através do discurso que construímos nossas relações com as pessoas, que nos identificamos política e socialmente, que reconhecemos as vozes e somos representados por elas; que construímos significados, a fim de nos enxergarmos e nos conceituarmos.

FAIRCLOUGH (2001, p. 92) acrescenta que a prática discursiva:

é constitutiva tanto de maneira convencional como criativa: contribui para reproduzir a sociedade (identidades sociais, relações sociais, sistemas de conhecimento e crença) como é, mas também contribui para transformá-la.

Assim, não é só o discurso que é moldado, nós, como sujeitos, também somos. Estamos, a todo o momento, sendo (re)criados pelos discursos. Como vemos em ORLANDI (1998, p. 75),

O sujeito é um lugar de significação historicamente constituído, ou seja, uma "posição". Essas posições, como sabemos, correspondem mas não equivalem à simples presença física dos organismos humanos (empiricismo) ou aos lugares objetivos da estrutura social (sociologismo). São lugares "representados" no discurso, isto é, estes lugares estão presentes mas transformados nos processos discursivos.

Dessa maneira, se não nos vemos representados socialmente, dificilmente vamos nos reconhecer como pessoas diferentes. Partilhando, também, desse entendimento, a natureza socioconstrucionista dos discursos, LOPES (2002, p. 31) nos diz que é a partir do discurso do outro que nos compreendemos enquanto sujeitos:

O discurso como uma construção social é, portanto, percebido como uma forma de ação no mundo. Investigar o discurso a partir dessa perspectiva é analisar como os participantes envolvidos na construção do significado estão agindo no mundo por meio da linguagem e estão, desse modo, construindo sua realidade social e a si mesmos. 
O autor trata da importância do debate acerca da construção social ainda dentro de sala de aula, uma vez que além de ser um espaço heterogêneo, é também um lugar para ampliar a criticidade do aluno.

A percepção do discurso como construção social coloca as pessoas como participantes nos processos de construção do significado na sociedade e, portanto, inclui a possibilidade de permitir posições de resistência em relação a discursos hegemônicos, isto é, o poder não é tomado como monolítico e as identidades sociais não são fixas. (LOPES, 2002, p.55)

Dessa forma, o não dito também significa, já que, para ser um enunciado, basta produzir sentido. A pesquisadora ORLANDI (1998, p. 75) acerca da produção discursiva, esclarece que: "não há sentido que não tenha sido produzido em condições específicas, em uma relação com a exterioridade, com uma direção histórico-social que se produz em relações imaginárias que derivam de um trabalho simbólico".

Os sentidos que são produzidos a partir de uma leitura homogênea de igualdade entre as pessoas e que são constantemente reproduzidos na sociedade e, inclusive, na escola não reconhecem os outros e suas diferenças étnicas, sociais e culturais.

É no campo do discurso que reconhecemos tradições e ideologias. Através dele nos afirmamos e é por isso tão importante na construção da sociedade. Nas palavras do filósofo FOUCAULT (2004, p. 10), “O discurso não é simplesmente aquilo que traduz as lutas ou o sistema de dominação, mas aquilo por que, pelo que se luta, o poder do qual nos queremos apoderar."

Por isso, a construção de um currículo multicultural crítico nos parece ser uma das formas de luta contra os discursos hegemônicos vigentes tanto na formação docente quanto nas práticas pedagógicas em sala de aula. Auxiliando a produção de novos discursos que tratem e deem voz aos que estão à margem na sociedade.

\section{Política e currículo}

Muda-se currículo, retiram disciplinas, e criam muito marketing, na maioria das vezes, sem o envolvimento da comunidade escolar e dos profissionais da área educacional. Assim, a legitimidade discursiva está entrelaçada com os poderes político, econômico e social vigentes.

Um exemplo disso é a Reforma do Ensino Médio de 2017, que retira a obrigatoriedade de algumas disciplinas no ensino básico dos alunos, 
fazendo-os optar por certos conhecimentos em detrimento de outros. Sem a participação decisória da comunidade escolar representa, certamente, a continuidade da reprodução da homogeneização cultural.

Dentro desse contexto, podemos ver que é pouco viável que ocorra um diálogo entre a comunidade escolar e os governantes, como também percebemos a falta de representação desses segmentos dentro da política, uma vez que nos últimos anos, observamos que o cargo de ministro da educação esteve ocupado majoritariamente por pessoas não pertencentes à área da educação. Passou por: Henrique Paim (2014-2015) formado em economia; Cid Gomes (2015) formado em engenharia civil; Renato Janine (2015 - 5 meses no cargo) formado em filosofia; Aloizio Mercadante (2015-2016) formado em economia e Mendonça Filho (2016-2018) formado em administração de empresas.

Diante de tal realidade, o educador Tomaz Tadeu da Silva em seu livro intitulado "O currículo como fetiche" (2001) nos ajuda a repensar um currículo de cunho representativo e multicultural.

Segundo o autor supracitado,

Na perspectiva pós-estruturalista, conhecer e representar são processos inseparáveis. A representação - compreendida aqui como inscrição, marca, traço, significante e não como processo mental - é face material, visível, palpável, do conhecimento. A "crise" de legitimação que está no centro das nossas formas de conhecer o mundo está, pois, indissoluvelmente ligada à "crise" no estatuto da representação - nossas formas de representar o mundo. (SILVA, 2001, p.32)

É a partir do conhecimento que podemos compreender melhor quem somos, a nossa língua, história, cultura, permite-nos reconhecer o nosso lugar de fala, legitima a nossa voz para que os questionamentos dos sujeitos que estão à margem na sociedade possam ser ouvidos.

Logo, quando falamos de currículo, estamos falando de política. E, como professores, cabe a nós reivindicar a liberdade discursiva para que os alunos tenham acesso a todos os tipos de conhecimento e assim se reconheçam e se representem.

Em Silva (2001), podemos ver que há dois conceitos de representação: a por "delegação", que é a necessidade de uma só pessoa representar, ter a voz de um grupo; e a por "descrição", que é a forma como os grupos sociais e suas culturas são exteriorizados, vistos ou apresentados nos discursos e meios de comunicação. 
O currículo, assim como os comerciais, novelas, propagandas, e tantos outros gêneros, serve para manter e reproduzir discursos que constroem sujeitos, e esses podem ser representados dentro da sociedade ou não.

Nossa "democracia representativa" ${ }^{3}$ mostra que no grupo "ideal" de representação não entram vozes de mulheres, nordestinos, negros, latinos, homossexuais, pobres; apesar de muitos desses segmentos sociais serem maioria numericamente, são sempre excluídos quando se trata de políticas públicas.

O currículo pode transformar as formas de representação impostas politicamente, economicamente e socialmente durante anos, a fim de reconhecer e ouvir a voz da comunidade escolar, que envolve todos os participantes no processo de ensino e aprendizagem, que sempre estiveram à margem das discussões da construção curricular.

No entanto, não devemos discutir a representação sem mencionar o processo de significação. Nas palavras de $\operatorname{SILVA}$ (2001, p. 36),

Como sabemos, Saussure, tendo como foco a língua, destacou o caráter arbitrário do signo. Não existe nenhuma relação intrínseca, "natural", entre significante e significado: um significante determinado deve sua forma e sua conexão com um determinado significado exclusivamente à convenção social. Não há nada que "naturalmente" determine que o significante "rosa" (oral ou escrito) tenha, na língua portuguesa, essa forma e que esteja ligado ao significado "rosa".

À medida que entramos em contato com as palavras, com as pessoas, tecnologias e afins, estamos sujeitos aos significados construídos pela sociedade. E, dessa forma, somos nós que atribuímos sentido ao léxico, aos discursos que ouvimos e nos identificamos.

$\mathrm{O}$ autor nos esclarece que:

(...) o vínculo que se estabelece entre significante e significado é sempre resultado de uma construção social, isto é, esse vínculo nunca é "natural". Sobretudo naquilo que interessa à nossa compreensão da representação, os signos são o que são e significam o que significam porque nós os fizemos assim. (SILVA, 2001, p.37)

Logo, o currículo é também uma ferramenta utilizada nas formas de representação, porém está vinculado aos significados, de um poder

\footnotetext{
${ }^{3}$ Silva (2001) utiliza esse termo para tratar dos conceitos de representação, retomando o regime político que foi caracterizado como "democracia representativa".
} 
hegemônico, que predominam na nossa história e discriminam diversas classes da sociedade, excluindo os que são diferentes.

Significantes como gordo, negro, gay, latino, entre tantos outros, possuem, em determinados discursos, significados de cunho pejorativo porque foram construídos para serem reproduzidos dessa maneira.

Ainda segundo o autor,

Os sistemas de significação são descritos como sendo tão dependentes dos códigos, das convenções, das estilísticas e das estruturas que dirigem sua produção que só podem significar uma coisa: aquilo que, precisamente, no momento e no ato de sua produção, está determinado por esses recursos semióticos. (SILVA, 2001, p.37)

Faz-se necessário ir além da reflexão acerca da solidez dos discursos preconceituosos, temos de trazer os discursos excludentes e questioná-los; produzir materiais que abordem esses temas dentro da academia, na formação dos docentes, e para além de ser um discurso acadêmico, temos de fazer com que chegue à comunidade escolar, para que os alunos produzam, editem, façam-se ouvir.

Só quem se insere nos contextos e reconhece o seu lugar de fala produz textos coerentes, mantendo a alteridade, com posições sociais e políticas diferentes, mas reconhecendo o outro e o seu direito de produção discursiva.

Quando os governantes falam em reformas educacionais, ao analisarmos o discurso, devemos atentar para as intenções dos autores e seus efeitos para chegar ao objetivo desejado.

Não podemos nos esquecer de que a representação só ocorre por causa do poder do discurso, se as classes marginalizadas não tiverem acesso aos textos diferentes daqueles que fomos habituados a conviver, e por isso, já estão naturalizados em nossos discursos, as relações de poder serão reproduzidas.

SILVA (2001, p. 48) nos esclarece que:

O poder está situado nos dois lados do processo de representação: o poder define a forma como se processa a representação; a representação, por sua vez, tem efeitos específicos, ligados, sobretudo, a produção de identidades culturais e sociais, reforçando, assim, as relações de poder. A representação, entretanto, não é apenas um condutor do poder, um simples ponto na mediação entre o poder como determinante e o poder como efeito. O poder está inscrito na representação: ele está "escrito", como marca visível, legível, na representação. 
Diante do exposto, o currículo seria, então, uma das formas de reivindicação para quebrar uma hegemonia representativa reproduzida por anos. A nossa identidade para ser construída depende da relação com aquele que é diferente de mim, com o outro, sem nos distanciar do respeito mútuo, e, principalmente, nos chocando com os diversos tipos de violência simbólica e física que ocorrem diariamente por conta de preconceitos.

O sociólogo HALL (2006, p. 13) nos trouxe reflexões acerca das identidades fragmentadas pós-modernas, segundo ele, nossa identidade não é imutável, pois estamos a todo o momento sendo construídos enquanto sujeitos a depender das experiências vividas, do contexto social, da formação acadêmica, entre outros espaços.

A (re)construção dos conceitos cujos significados inferiorizaram diversas classes sociais é imprescindível. É necessário que essas vozes que, por muito tempo foram silenciadas, apareçam em cena, tenham espaço para se fazer enxergar, e tragam consigo sua história, cultura, língua, imagem e indagações.

Deve-se repensar o currículo de modo que possamos incluir culturas, e discutir os apagamentos de classe na história; recriar os significados e promover questionamentos nos alunos.

Nas palavras de SILVA (2001, p. 68),

Como representação, o currículo está diretamente envolvido nesse processo. E aqui, nessa interseção entre representação e identidade, que o currículo adquire sua importância política. A representação, em conexão com o poder, está centralmente envolvida naquilo que nos tornamos. Não há identidade nem alteridade fora da representação. $\mathrm{O}$ currículo é, ali, naquele exato ponto de interseção entre poder e representação, um local de produção da identidade e da alteridade. E precisamente, aqui, nesse ponto, que o currículo, tal como o conhecimento, se torna um terreno de luta em torno da representação.

Portanto, não existe mudança no currículo que não seja ideológica e política. Voltando para o objetivo central, a formação docente, repensar o currículo como representação é sem dúvida contribuir para um processo de formação mais crítico, político e comprometido socialmente. 


\section{Ensino da língua espanhola e a reforma do ensi- no médio de 2017}

De acordo com alguns autores (Tomaz Tadeu, Canen, Moreira, entre outros), o currículo é uma das formas de luta social, é uma ferramenta política de construção da sociedade. Para SILVA (2010), o currículo não está dissociado das relações de poder da sociedade.

Segundo o autor,

O currículo é sempre o resultado de uma seleção: de um universo mais amplo de conhecimento e saberes seleciona-se aquela parte que vai construir, precisamente o currículo. As teorias do currículo, tendo decidido quais conhecimentos devem ser selecionados, buscam justificar por que "esses conhecimentos" e não "aqueles" devem ser selecionados. (SILVA, 2010, p.15)

Sendo assim, toda seleção curricular requer um posicionamento ideológico, pois está ligada às formas de poder e, consequentemente, a economia também.

A medida provisória que trata da reforma do ensino médio, sancionada em 2017, pelo ex-presidente da República, Michel Temer, traz muitas mudanças no currículo das escolas, principalmente, das públicas.

O foco deste tópico é refletir sobre a exclusão do Espanhol da grade curricular do ensino médio e suas consequências na vida dos alunos, professores (futuros) de línguas, como podemos ver no texto a seguir retirado da página do senado na internet:

O currículo será dividido entre conteúdo comum e assuntos específicos de acordo com o itinerário formativo escolhido pelo estudante (linguagens, matemática, ciências da natureza, ciências humanas e formação técnica).

Português e Matemática continuam obrigatórios nos três anos do ensino médio, assegurado, às comunidades indígenas, o ensino de línguas maternas. $\mathrm{O}$ texto reinclui como disciplinas obrigatórias Artes e Educação Física, que tinham sido excluídas pelo texto original da MP. Entre as línguas estrangeiras, o Espanhol não será mais obrigatório, ao contrário do Inglês, que continua obrigatório a partir do $6^{\circ}$ ano do ensino fundamental. (SENADO, 2017) 
É uma medida que reforça a exclusão para a grande maioria da população brasileira; aumenta o discurso com viés tecnicista do ensino de língua estrangeira; mantém o discurso estereotipado de igualdade social e étnica; exclui o multiculturalismo hispânico e afasta ainda mais a visão do brasileiro como latino americano.

Como vemos em SANTOS \& SILVA (2017, p. 76),

O Sindicato Nacional dos Docentes das Instituições de Ensino Superior-ANDES considera a não obrigatoriedade das disciplinas, articulada aos cortes de verbas, como um dos aspectos mais perversos da mercantilização da educação: ambas buscam a gradativa eliminação de conteúdo. A flexibilização nada mais é do que a retirada da oferta das disciplinas do currículo visando a economia de gastos. De acordo com o sindicato, o objetivo da MP 746/2016 é ofertar formação de maneira unilateral e linear, para o mercado de trabalho, aos filhos dos trabalhadores.

Na prática, a língua espanhola sai e fica o ensino da língua inglesa. $\mathrm{O}$ que de fato precisa ser questionado e debatido não é a permanência do Inglês como língua estrangeira, mas a retirada do Espanhol do ensino médio, uma vez que acreditamos que o hibridismo cultural é importante e necessário no ensino-aprendizagem.

Um dos problemas decorrentes disso é o alunado não se reconhecer como latino-americano, não saber a história de seu país e dos países fronteiriços, não se identificar com as diferentes culturas, acreditar em uma única identidade, não se enxergar como diferente; além de não ter condições de ingressar na faculdade optando pelo Espanhol nos processos seletivos sem ter tido contato com ele no ensino básico, obrigando-o a utilizar o Inglês, como por exemplo, no ENEM (Exame Nacional do Ensino Médio).

É uma atitude política, ideológica, visando à economia, mas que interfere na educação de milhões de brasileiros, e que não foi dialogada com tempo hábil para debates com os principais interessados na questão: os educadores, alunos e responsáveis.

\section{Ensino de espanhol: perspectiva multicultural crítica}

Os temas cultura e multiculturalismo ganharam força nos últimos anos, entretanto existem várias vertentes de estudo. Como vemos em MOREIRA (1999, p. 1), “' a cultura é uma prática produtiva, um espaço 
constituidor, que dispõe de relativo grau de autonomia em relação à esfera econômica". Por isso, é um campo disputado ideologicamente, pois nele podemos encontrar diversas formas de representação.

Ainda segundo o autor,

De fato, não há quem hoje subestime os confrontos e os problemas decorrentes da presença maciça, principalmente nos países do chamado Primeiro Mundo, de grupos sociais cujas produções culturais, etnias, crenças e condutas diferem das associadas aos grupos dominantes. As formas de vida e as culturas desses últimos grupos são tidas como os únicos padrões aceitáveis, ao passo que as dos outros, as dos marginais, são vistas como uma ameaça à homogeneização cultural perseguida, o que faz com que sejam desvalorizadas, desrespeitadas e reprimidas. (MOREIRA, 1999, p.2)

De acordo com MCLAREN (2000), existem quatro tipos de multiculturalismo: o conservador/empresarial, que se baseia na superioridade étnica, na discriminação; o humanista liberal, que acredita na igualdade entre todas as pessoas e povos; o liberal de esquerda, que vê a diferença cultural, mas a trata como essência; e o crítico, que pensa o processo de representação decorrente das lutas sociais.

Neste trabalho, ficamos com a perspectiva de currículo multicultural crítico, pois segundo SILVA (2010, p. 89),

Um currículo inspirado nessa concepção não se limitaria, pois, a ensinar a tolerância e o respeito, por mais desejáveis que isso possa parecer, mas insistiria, em vez disso, numa análise dos processos pelos quais as diferenças são produzidas através de relações de assimetria e desigualdade. Num currículo multiculturalista crítico, a diferença mais do que tolerada ou respeitada, é colocada permanentemente em questão.

Devemos perceber que nossas identidades são construídas e não são imutáveis. Que são resultados de processos de significação, de representação. Nas palavras de MOREIRA (1999, p. 3),

O multiculturalismo crítico rejeita tanto o foco liberal na igualdade entre as culturas como a ênfase na diferença por parte da corrente liberal de esquerda. Considera que as duas posições configuram uma falsa oposição e que ambas refletem uma lógica essencialista que toma as identidades individuais como autônomas, auto-suficientes e autodirecionadas. Argumenta que a diversidade não constitui um fim em si mesma, precisa ser afirmada no interior de uma política de crítica cultural e de compromisso com a justiça social. Ou seja, vê a diferença 
sempre como produto da história, da cultura, do poder e da ideologia. Daí a abordagem da diferença com base em uma perspectiva de mobilização política.

Há duas concepções de multiculturalismo crítico: a pós-estruturalista e a materialista. Neste trabalho, ficaremos com a definição do multiculturalismo crítico pós-estruturalista por se relacionar com a construção discursiva. Nas palavras de SILVA (2010, p. 87),

Para a concepção pós-estruturalista, a diferença é essencialmente um processo linguístico discursivo. A diferença não pode ser concebida fora dos processos linguísticos de significação. A diferença não é uma característica natural: ela é discursivamente produzida.Ou seja, à medida que não encontramos a representação das diferentes culturas, pessoas, histórias, no ensino de línguas; a percepção, o reconhecimento das diferenças, o processo de identificação, também não acontecem por parte dos alunos.

Sobre a segunda concepção, a "materialista", o autor supracitado ainda discorre que: "em geral inspirada no marxismo, enfatiza, em troca, os processos institucionais, econômicos, estruturais que estariam na base da produção dos processos de discriminação e desigualdade baseados na diferença cultural”. (SILVA, 2010, p. 87)

$\mathrm{O}$ ensino de línguas no Brasil está indissoluvelmente ligado ao mercado de trabalho, tanto na procura de empregos quanto pelo víeis político e econômico de quem governa o país, mas, certamente, não deveria ser apenas por esse motivo o interesse em aprender outra língua.

Estamos dentro de um continente que fala espanhol e, no entanto, acredita-se que não é preciso aprender a língua espanhola. Acredita-se numa superioridade política, econômica, geográfica em relação aos países que nos fazem fronteira, porque criaram a ideia de disputa entre nós.

Mas, o que de fato precisa ser enfatizado e questionado no ensino-aprendizado de línguas são nossas identidades e diferenças, são a nossa história e o que temos em comum com nossos vizinhos latinos, nossa colonização, as violências culturais e sociais, a política e a economia que nos aproximam. Precisamos nos construir e nos identificar com essas histórias para além do pensamento mercadológico, competitivo, que relacionaram com o ensino de línguas.

Diante do exposto, faz-se necessário rever nossas práticas sociais, a fim de se criar novos discursos, demonstrar quão diversa é nossa cultura 
e quantas vozes são apagadas no processo de representação. Dessa forma, pensar um currículo multicultural crítico na formação docente como forma de resistência, em busca do reconhecimento da diversidade cultural.

\section{Análises das grades curriculares na formação docente}

Visando a reflexão do currículo, selecionamos as grades curriculares e ementas dos cursos de licenciatura em Letras/Espanhol de quatro universidades públicas do estado do Rio de Janeiro: UFRRJ (Universidade Federal Rural do Rio de Janeiro), UFF (Universidade Federal Fluminense), UERJ (Universidade do Estado do Rio de Janeiro) e UFRJ (Universidade Federal do Rio de Janeiro). Para pensarmos sobre o ensino multicultural, uma vez que precisamos avançar bastante na prática, a fim de que as demandas salientadas pela perspectiva multicultural crítica sejam alcançadas.

Segundo MCLAREN (2000, p. 123),

A perspectiva que estou chamando de multiculturalismo crítico compreende a representação da raça, classe e gênero como resultados de lutas sociais mais amplas sobre os signos e significações e, neste sentido, enfatiza não apenas o jogo textual e o deslocamento metafórico como forma de resistência (como no caso do multiculturalismo liberal de esquerda), mas enfatiza a tarefa central de transformar as relações sociais, culturais e institucionais nas quais os significados são gerados.

A primeira instituição a ser analisada, a UFRRJ, possui a carga horária total de $3280 \mathrm{~h}$, com 156 créditos ao todo e 8 períodos previstos. Apresenta duas disciplinas especificamente destinadas à cultura hispânica, somadas $120 \mathrm{~h}$ de carga horária e 8 créditos. Elas são vistas no $6^{\circ}$ e $7^{\circ}$ períodos. Dentro de sua grade curricular, encontramos a disciplina "ensino de língua espanhola" até o $6^{\circ}$ período, porém essas dão conta do ensino da língua, e têm conteúdos mais gramaticais.

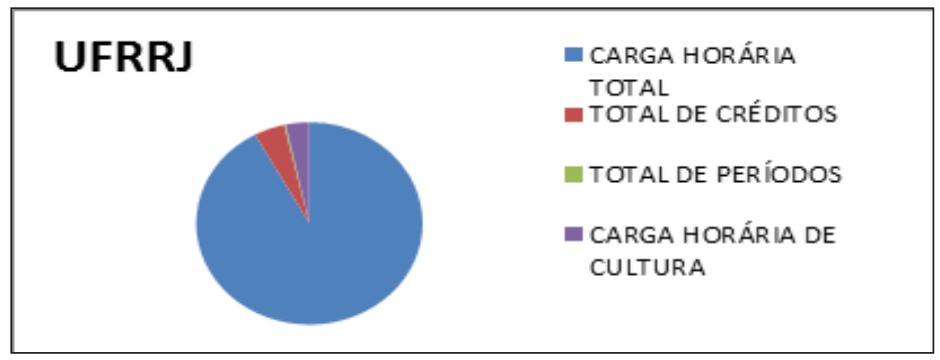

Gráfico 1 
A UFF apresenta uma carga horária de $3360 \mathrm{~h}$, prevista para 10 períodos letivos, com duas disciplinas específicas que tratam de cultura: matrizes culturais espanholas e matrizes culturais hispano-americanas, que juntas somam $120 \mathrm{~h}$.

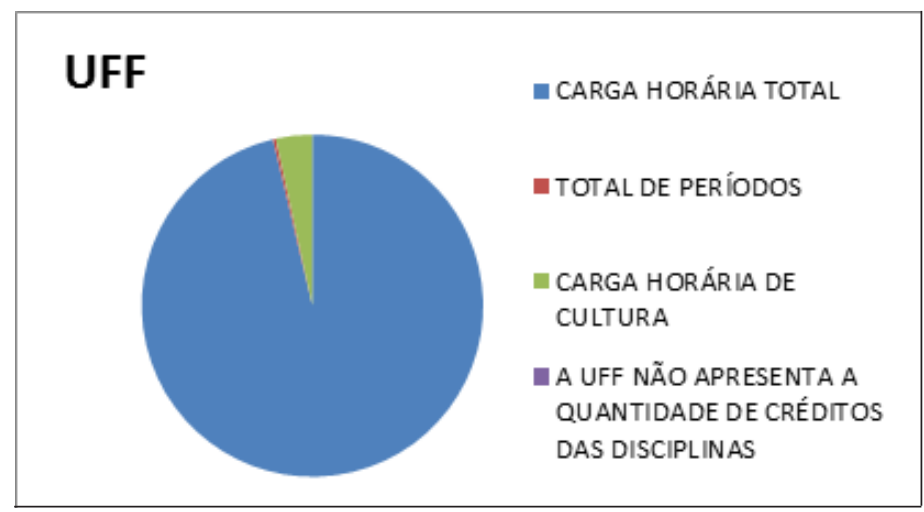

Gráfico 2

A UERJ tem a carga horária total do curso: $3800 \mathrm{~h}$ e total de créditos: 212 créditos a serem realizados no mínimo de 8 períodos. Apresenta duas disciplinas intituladas como "cultura hispânica", a primeira no $3^{\circ}$ período e a segunda no $4^{\circ}$, ambas com 2 créditos.

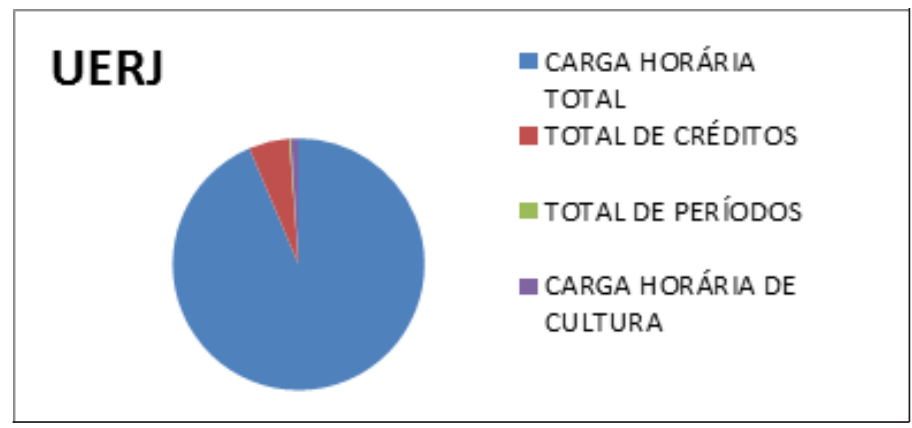

Gráfico 3

A UFRJ apresenta o maior currículo de letras/espanhol entre elas com 242 créditos e carga horária de 4.290 horas. Apresenta duas disciplinas específicas envolvendo cultura: fundamentos da cultura espanhola, no 
$3^{\mathrm{a}}$ período, com 4 créditos e cultura e civilização da América latina, no $5^{\circ}$ período, também com 4 créditos. Há também ensino de língua espanhola em todos os períodos; matérias voltadas para o latim, frequentemente visto em todas as grades do curso de letras e grego genérico como disciplinas obrigatórias.

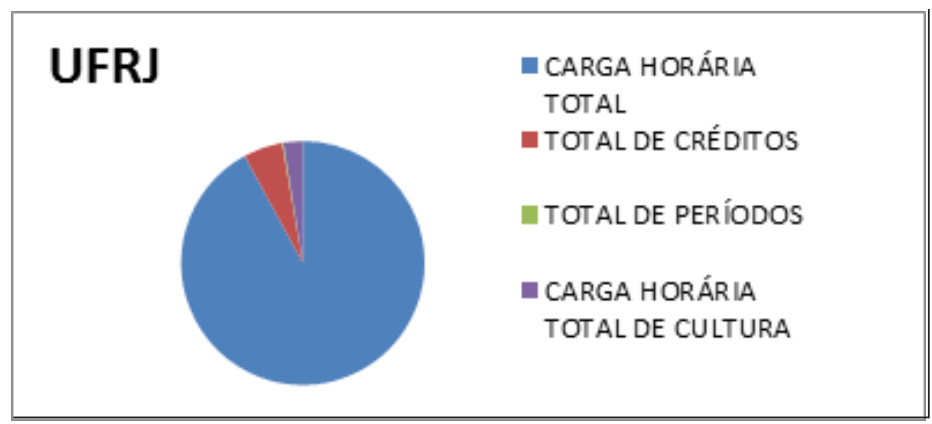

Gráfico 4

Vejamos no quadro comparativo a representação dessas informações:

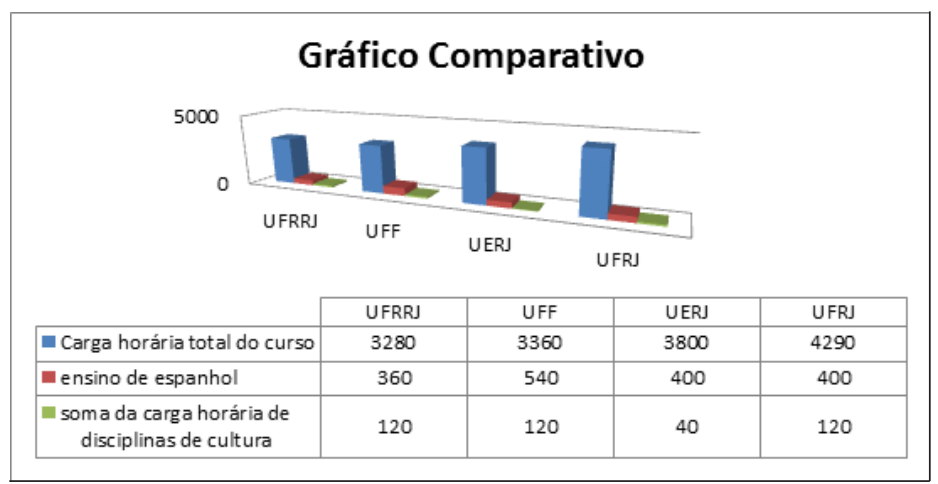

Gráfico 5

O gráfico 5 nos mostra a quantidade de horas que é atribuída às disciplinas obrigatórias destinadas ao ensino do espanhol em vermelho, com ênfase na estrutura da língua espanhola e, em verde, ao ensino cultural da língua. Em azul, é a soma da carga horária total dos cursos de Letras/Espanhol. 
Nas grades curriculares, na formação dos professores, vemos que existe tempo, ainda que curto, reservado ao ensino de cultura, porém nada específico que trate de multiculturalismo crítico. Analisando esses documentos, percebemos que há certa predominância do ensino hispânico em detrimento do espanhol latino americano.

Apesar da UFRJ possuir a maior carga horária do curso de Letras/Espanhol, o tempo destinado à cultura hispânica é equivalente ao da UFRRJ e UFF. A UERJ possui a segunda maior carga horária total do curso, mas é a que reserva a menor carga horária ao ensino cultural. Igualando-se no número de horas destinadas ao ensino gramatical com a UFRJ.

Entendemos que, para o ensino-aprendizado do espanhol, é necessário que tenhamos mais tempo para debates acerca da diversidade, da alteridade, do multiculturalismo crítico, de resistência, e é evidente que a faltam esses questionamentos na formação docente, afetando as nossas práticas. 
Vejamos a ementa da disciplina "Cultura Hispânica I", da UFRRJ. Como objetivos que a disciplina pretende alcançar está o "reconhecimento e valorização das múltiplas manifestações culturais", talvez o termo mais adequado para trabalharmos a diversidade cultural não seja "valorização", uma vez que elas estão postas, existem, o que devemos fazer é reconhecer e questioná-las. (SILVA, 2000).

\begin{tabular}{|l|c|}
\hline $\begin{array}{l}\text { CODIGO:IM836 } \\
\text { CREDTTOS: } 04\end{array}$ & $\begin{array}{c}\text { CULTURA HISPANICA I } \\
\text { (4T-OP) }\end{array}$ \\
\hline
\end{tabular}

\begin{tabular}{|l|}
\hline INSTITUTO MULTIDISCIPLINAR \\
\hline DEPARTAMENTO DE TECNOLOGLAS E LINGUAGENS \\
\hline
\end{tabular}

OBUETIVO DA DISCIPLINA:

Desenvolver no aluno a capacidade de reconhecer e valorizar as múltiplas manifestacóes culturais dos povos de lingua espanhola, analisando suas riqueza, diferenças e unidade.

EMENTA:
Contextualizacł̇o e panorama social, politico, histórico e geografico do mundo hispànico.
Pluralidade linguistica, heterogeneidade e hibridismo cultural.

\section{CONTEÚDO PROGRAMÁTICO:}

1. A cultura taurina na Espanha desde sua origem até a contemporaneidade.

2. A Conquista e a Reconquista de Espanha.

3. 1492 como o ano decisivo: unidade espanhola e desintegraçào do mundo

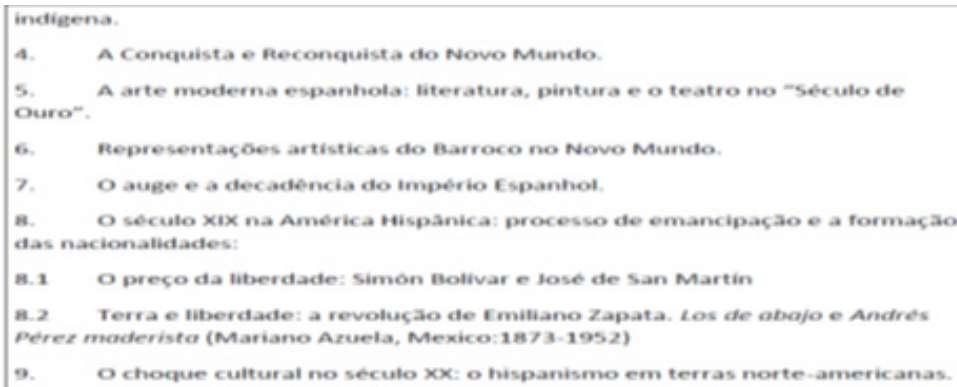


Analisando mais atentamente, percebemos que não há temas que tratem de identidade, diferença, pertencimento, por exemplo; ainda que estejam destacados a heterogeneidade, a pluralidade linguística e o hibridismo cultural.

Vejamos a ementa da UERJ que também não difere dessa linha. Propõe-se a identificar geograficamente os países que têm o espanhol como língua materna e suas relações políticas.

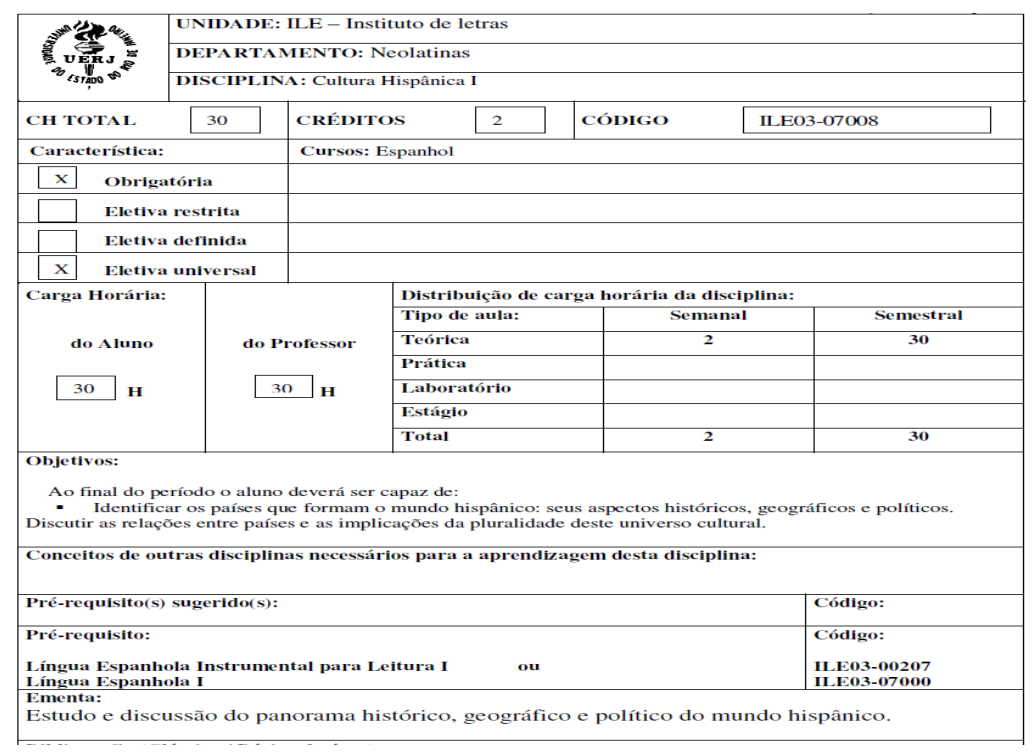




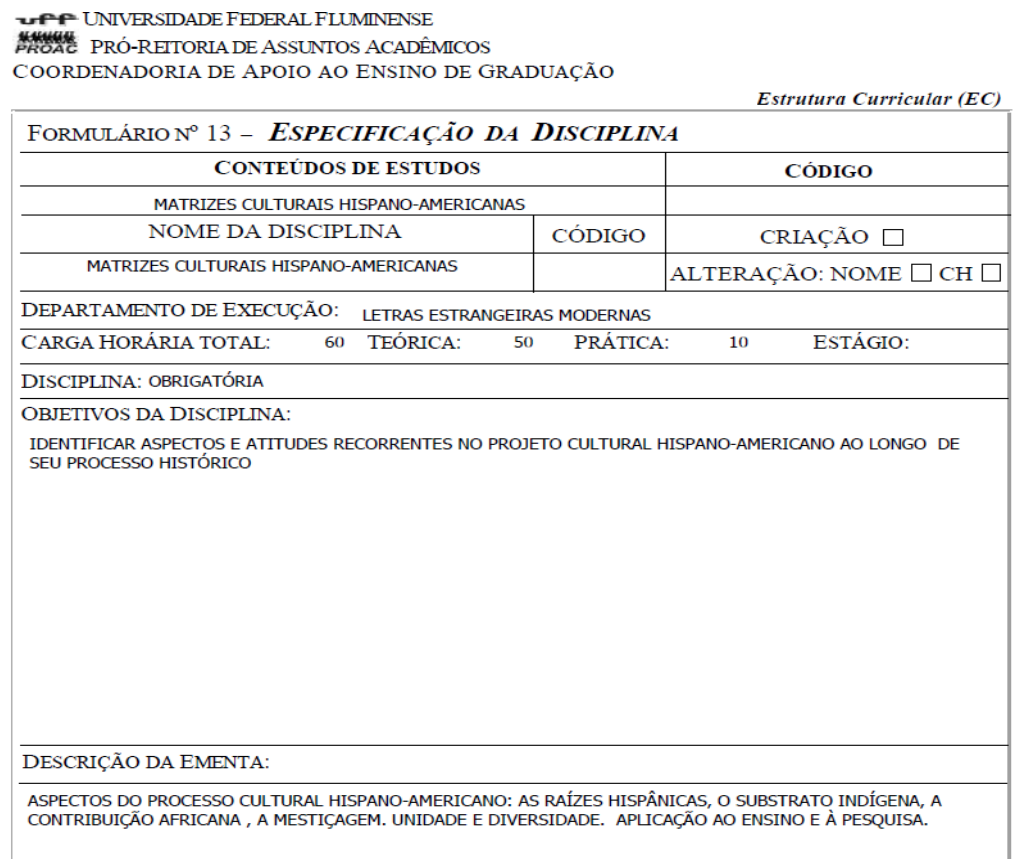

A UFF apresenta em "matrizes culturais espanholas" as "diversas fontes configuradoras da cultura espanhola", e em "matrizes hispano-americanas" se propõe a "identificar aspectos e atitudes recorrentes no projeto cultural hispano-americano ao longo de seu processo histórico".

Vejamos as disciplinas citadas:

Percebemos que na segunda disciplina aparecem a "unidade e diversidade", "a contribuição africana", "a mestiçagem" etc. Certamente, é importante que questionamentos acerca desses temas sejam feitos, se quisermos mostrar o quão conflituosas são as relações sociais; o quão violenta foi a "descoberta" da América Latina; que conceito de "contribuição" está sendo pensado; como é importante a manutenção desses discursos que foram construídos em cima de uma ideia de subjetividade fixa, que exclui a história do sujeito que está à margem, o diferente e sua identidade.

As ementas desses cursos nos mostram que o fato de ter cultura no nome da disciplina, não indica que esteja incluindo a diversidade, refletindo, principalmente questionando a homogeneização cultural existente, produzindo novos discursos, ou seja, o tipo de multiculturalismo utilizado, na maioria das vezes, não é o crítico. 
No entanto, esse trabalho visa fazer uma crítica construtiva para o currículo da formação docente do curso de Espanhol, para fomentar questionamentos e refletir sobre a reprodução dos discursos hegemônicos, euros-centrados. Assim, não há intenção de nivelar as universidades e suas disciplinas.

Cabe ressaltar que as análises foram baseadas nas grades curriculares e ementas dos cursos e não na prática em sala de aula, e que se faz necessária uma pesquisa mais abrangente sobre o currículo na formação dos professores de línguas, sobretudo para fazermos uma análise da perspectiva do ensino de Espanhol no Brasil.

\section{Considerações finais}

Como vimos, o multiculturalismo crítico se diferencia dos outros tipos porque visa não apenas refletir e valorizar as diferenças culturais, étnicas, de gênero, mas reconhecer que elas existem e questioná-las, para que as construções discursivas e as formas de poder que permeiam o ensino-aprendizagem possam ser debatidas e transformadas.

Acreditamos na importância do reconhecimento das diferenças através da representação de variados discursos, que promovam um debate crítico e respeitoso dentro da sala de aula, a fim de minimizar as relações conflituosas existentes no espaço escolar e também fora dele.

Assim, faz-se necessário identificar as práticas sociais conservadoras e excludentes que foram construídas no decorrer do tempo através do discurso legitimado por classes políticas e economicamente detentoras do poder em nossa sociedade. Para que, como educadores, perpassemos o ensino da estrutura linguística no ensino de línguas e possamos contribuir para a visibilidade dos discursos de determinados segmentos sociais silenciados na nossa história.

A construção do currículo multicultural crítico pode transformar a realidade das margens, uma vez que, nessa perspectiva, elas podem, para além de se verem representadas, se auto representarem; podem produzir seu próprio discurso de resistência.

Esta pesquisa demonstrou que os currículos voltados para a formação docente ainda privilegiam uma perspectiva de currículo que não promove questionamentos acerca da construção das identidades, das formas de representação, das diferenças culturais dentro da sociedade, deixando de lado os aspectos multiculturais.

Nesse sentido, debater a construção do currículo de língua, ainda 
na formação docente, também é uma forma de produção de um novo discurso. Um discurso que questione as formações ideológicas presentes nas representações culturais, a fim de que identidade, subjetividade, diferenças possam ser vistas como imprescindíveis na nossa construção como sujeitos.

\section{REFERÊNCIAS}

BAKHTIN, Mikhail Mjkhailovitch. Estética da criação verbal. 2' ed. São Paulo Martins Fontes, 1997. (Coleção Ensino Superior).

Currículo sem Fronteiras, v.6, n.2, pp.98-113, Jul/Dez 2006. Disponível em:

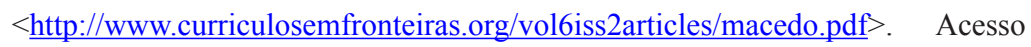
em: 04 de outubro de 2017.

FAIRCLOUGH, Norman. Discurso e mudança social. Brasília: Editora Universidade de Brasília, 2001.

FOUCAULT, Michel. A ordem do discurso. Aula inaugural no College de France, 1970 .

HALL, Stuart. A identidade cultural na pós-modernidade. Tradução Tomaz

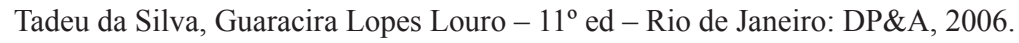

MCLAREN, Peter. Multiculturalismo crítico/ Peter McLaren; prefácio Paulo Freire; apresentação Moacir Gadotti; tradução Bebel Orofino Schaefer. 3. Ed. São Paulo: Cortez: Instituto Paulo Freire, 2000.

MINISTÉRIO DA EDUCAÇÃO. Disponível em: $<\underline{\text { http://portal.mec.gov.br/gabi- }}$

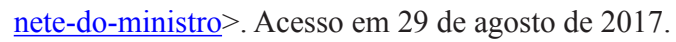

MOITA LOPES, Luis Paulo da. Identidades fragmentadas: a construção discursiva de raça, gênero e sexualidade em sala de aula. Campinas, SP: Mercado de Letras, 2002.

MOREIRA, Antonio Flavio Barbosa (Org.). Currículo: políticas e práticas. Campinas, SP: Papirus, 1999.

ORLANDI, Eni Pucinnelli. Discurso e argumentação: um observatório político. In Fórum Linguístico, Fpolis, n. 1 (73-81), jul.-dez. 1998. Disponível em: $<\underline{\text { ht- }}$ tps://periodicos.ufsc.br/index.php/forum/article/download/6915/6378 $>$. Acesso em: 04 de outubro de 2017.

PÁDUA, Elisabete Matallo Marchezine de. Metodologia da pesquisa: abordagem teórico-prática. 2. ed. Campinas: Papiros, 1997. 
SANTI, Heloise C. \& SANTI, Vilson J. C.. Revista Anagrama - Revista Interdisciplinar da Graduação. Ano 2 - Edição 1 - Setembro/Novembro de 2008.

SILVA \& KOCHE. Linguística aplicada ao português: morfologia. Cortez editora, 1983.

SILVA, Tomaz Tadeu da. Documentos de identidade: uma introdução as terias do currículo. - 3 ed -. Belo Horizonte: Autêntica, 2010.

. O currículo como fetiche: a poética e a política do texto curricular. - 2. Ed.- Belo Horizonte: Autêntica, 2001.

Recebido em: 31/07/2018

Aceito em: 26/03/2019 